\title{
Quantifying the Influence of Lightning Strike Pressure Loading on Composite Specimen Damage
}

\author{
P. Foster ${ }^{1} \cdot$ G. Abdelal ${ }^{1} \cdot$ A. Murphy ${ }^{1}$ (D)
}

Received: 11 January 2018 / Accepted: 21 March 2018 /Published online: 10 April 2018

(C) The Author(s) 2018

\begin{abstract}
Experimental work has shown that a component of lightning strike damage is caused by a mechanical loading. As the profile of the pressure loading is unknown a number of authors propose different pressure loads, varying in form, application area and magnitude. The objective of this paper is to investigate the potential contribution of pressure loading to composite specimen damage. This is achieved through a simulation study using an established modelling approach for composite damage prediction. The study examines the proposed shockwave loads from the literature. The simulation results are compared with measured test specimen damage examining the form and scale of damage. The results for the first time quantify the significance of pressure loading, demonstrating that although a pressure load can cause damage consistent with that measured experimentally, it has a negligible contribution to the overall scale of damage. Moreover the requirements for a pressure to create the damage behaviours typically witnessed in testing requires that the pressure load be within a very precise window of magnitude and loading area.
\end{abstract}

Keywords Lightning strike $\cdot$ Pressure loading $\cdot$ Composite damage $\cdot$ Finite element modelling

\section{Introduction}

Aircraft are on average subjected to lightning strikes once per year or every 1000 flight hours. For legacy metal aircraft when a strike occurs the lightning energy is rapidly conducted away from the attachment point around the aircraft due to the favourable conduction properties of the airframe aluminium materials. However when fibre reinforced plastic composite material is struck by lightning catastrophic damage may occur due to the relatively low conduction properties of the polymer resin constitutive [1]. Thus an additional protection material is required in the material construction, typically a surface metal mesh, to rapidly redistribute the intense charge and reduce the damage.

A. Murphy

a.murphy@qub.ac.uk

1 School of Mechanical and Aerospace Engineering, Queen's University Belfast, Ashby Building, Belfast, Northern Ireland BT9 5AH, UK 
There is still limited understanding of the damage mechanisms although a number of artificial lightning strike tests have been reported in the literature. Much of this lack of knowledge is due to the speed and intensity of the event which means it is very difficult to take physical measurements near the strike point during the strike. Post-test inspection of the damage is also difficult as there are a number of different surface and internal damage modes, which are difficult to differentiate between in a post-test inspection. A great number of variables are involved in lightning strike testing, the lightning waveform, specimen fixturing and location relative to the discharge probe, the protection system design, the composite materials and their stacking sequence. Together the small number of published test results and the volume of variables included in testing significantly increase the difficulty of establishing generic understanding from individual test results.

The potential of numerical simulations offer many advantages to study lightning strike events and the resultant damage creation. A significant advantage is the potential to scrutinise during the event the internal damage behaviour. In order to achieve this, a complete and accurate understanding of the loading mechanisms is needed in order to harness the significant advances available in composite material damage modelling [2-8]. This paper assesses the potential contribution of pressure loading to the damage of composite materials during a lightning strike by employing well-established and robust modelling approaches for composite damage prediction. The study examines the proposed pressure loads from the literature, modelling a test specimen and test setup with experimentally measured damage. It has been possible to compare the predicted damage considering each proposed load and to compare the predicted damage with the experimentally measured damage. Furthermore the range of loading parameters which result in representative experimental behaviour has been identified and the relative magnitude of damage compared to other loading mechanisms is established (i.e. thermal loading).

\section{Background}

Lightning is an electrostatic discharge resulting from a build-up of a differential charge between a cloud and earth or between clouds. An aircraft in proximity can become part of the discharge circuit resulting in an aircraft lightning strike. Once a discharge circuit is formed a massive flow of electric current occurs over a very short duration which superheats the conducting channel, forming a highly electrically conductive plasma channel. Where the conducting channel attaches to the aircraft significant local mechanical damage is possible (direct effects). The significant electric pulses passing through the aircraft structure can also interfere with and damage electronic systems etc. (indirect effects). This work specifically focuses on direct effects due to the cost and weight penalties associated with composite material lightning protection via the addition of an embedded surface metal mesh.

Direct lightning loading effects are typically described in two categories: Thermal loading, where the energy sources are the direct plasma heat flux and the Joule heating within the material [9]. Mechanical loading, where the energy sources are related to pressures resulting from arc channel attachment and expansion, along with pressures due to arc magnetohydrodynamic effects. The direct pressures are typically described as a radial pressure shockwave due to the rapid heating of the plasma channel (sometimes termed the acoustic load). An initial longitudinal pressure load is also envisaged as the plasma is formed along the lightning leader circuit. The magnetic induced pressures are due to Ampere's law and the current streamlines which are attracted and pull together due to the flow in the arc channel which further intensifies 
the arc channel pressure at the attachment point (magnetic pinch load). In addition the magnetic force induced by the current circulation also induces a mechanical pressure load in the arc column and in specimen material at the attachment point. Furthermore, the electric current flowing in the specimen directly acts to create an additional internal pressure load (termed the magnetic pressure) [9].

From measurements taken on test aircraft flown purposely into active lightning storms [10-14] the size of lightning impulse currents have been measured and standardised lightning intensity and current waveforms established for laboratory certification testing $[15,16]$. A small number of experimental studies have been published on composite materials which loosely adhere to the standardised certification waveforms and test setups. Munoz [17], as far as the authors can find, is the only published work to carry out the full Waveform-A load (peak current $200 \mathrm{kA}$ ) on a carbon fibre composite specimen. In this case $3 \mathrm{~mm}$ thick RTM (Resin Transfer Moulded) epoxy-carbon plate specimens were subjected to $200 \mathrm{kA}$ and $100 \mathrm{kA}$ simulated strikes. Kawakami $[18,19]$ carried out a comprehensive study of damage on press moulded and VARTM (Vacuum-Assisted Resin Transfer Moulded) epoxy-carbon specimens considering a range of current waveforms, material layups - providing detailed descriptions and measurements of resultant damage. Hirano [20] conducted low magnitude simulated strikes (20-40 kA) on pristine un-notched specimens again with a comprehensive description of the resultant damage. Feraboli $[21,22]$ tested a range of lightning loads $(10-50 \mathrm{kA})$ on pristine, un-notched, quasi-isotropic carbon fibre specimens and also investigated the damage effects when the specimens contained fasteners. Hosokawa [23] conducted simulated strikes on sandwich composite specimens (160 kA).

A number of authors have compared lightning strikes with transverse impact tests (Featherston et al., Evans et al. and Soulas et al. [24-26]). Both lightning strike and transverse impact tests result in significant matrix cracking however the position of damage differs considerably. The matrix cracking damage from a lightning strike test tends to be concentrated over the top plies only, akin to a high speed event with a small contact area, however the lightning strike damage does not occur through the thickness of the specimen, a characteristic not typical of significant transverse impact loading (high or low speed). Other notable works which have examine the damage mechanics and magnitudes include Gammon [27], Gineste [28], Yamashita [29] and Dong [30]. These studies examine individual loading scenarios but do not attempt to quantify how damage changes with load magnitude or load type.

The experimental studies have identified the main damage modes occurring in the form of fibre breakage and thermal decomposition, surface erosion, ply lift and internal matrix cracking (delamination and intralaminar cracking). However a significant range in the volume of each type of damage is found generally in the literature. Inconsistency in the measured damage is due to the variation in test setup, with authors using different intensity and current waveforms, varying distance between the specimen and the discharge probe, varying specimen fixturing and boundary conditions, and different material constituents and material layups, Table 1. An additional complexity is that authors do not have a consistent definition of damage and have measured using a range of techniques with different fidelity (surface visual inspection and image analysis, crosssection observation, ultrasonic scanning, micro X-ray inspection optical and electron microscopy).

Thus herein a single preceding experimental setup is modelled [20] in which the experimental arrangement and the damage measurements are fully defined. The experimental setup placed the composite specimen on a grounded copper sheet on a glass fibre composite test jig. A discharge probe tip was located approximately 2.0 to $3.0 \mathrm{~mm}$ from the specimen surface. The test specimen (a $4.704 \mathrm{~mm}$ thick laminate plate (IM600/133) with a stacking sequence of 


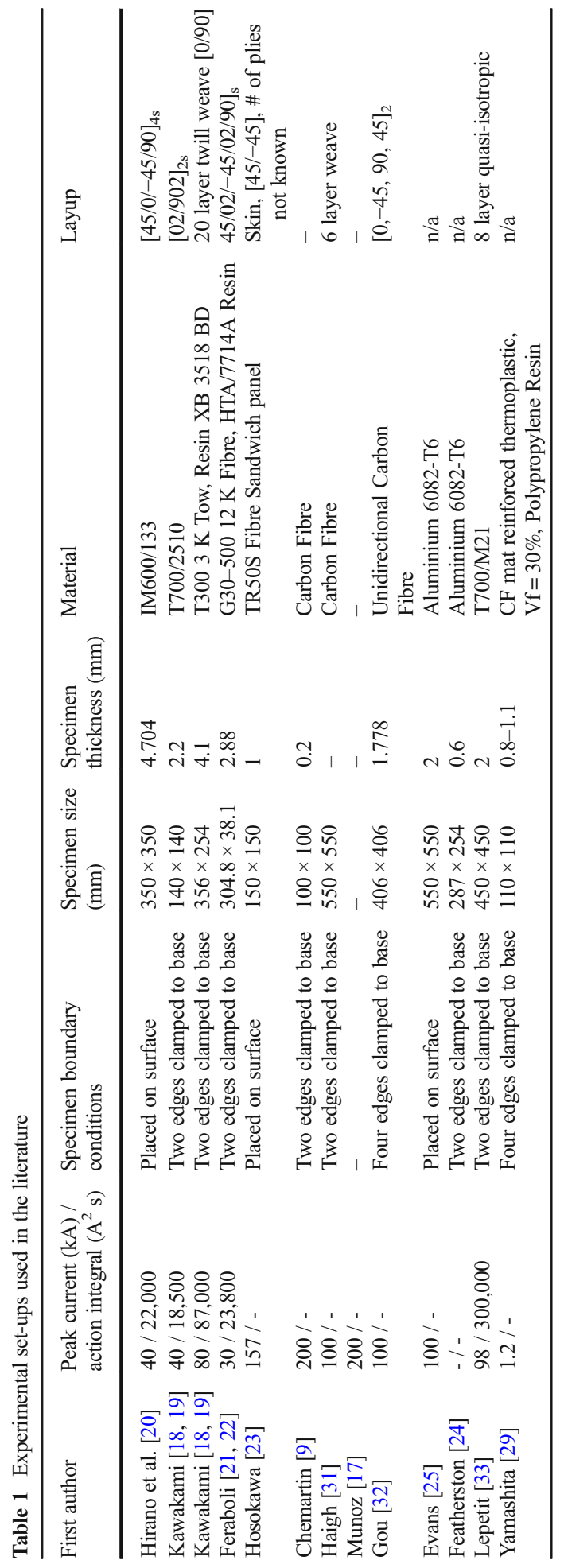


$(45 / 0 /-45 / 90)_{4 \mathrm{~S}}$ was subjected to a peak current of $40 \mathrm{kA}$, electrical charge of $0.85 \mathrm{C}$ and action integral of $22,000 \mathrm{~A}^{2} \mathrm{~s}$. The impulse waveform was developed to represent a first return stroke with a $4 \mu$ s rise time from $10 \%$ to $90 \%$ of the maximum current and a time of $20 \mu$ s to a post-peak 50\% maximum current. In order to aid the comparison between experimental and simulation predictions three damage areas are identified and key geometric features measured, Table 2. Note repeat tests suggest a moderate level of variation in the measured damage areas, with up to $33 \%$ in individual length dimensions.

In summary the experimental authors have noted probable or possible causes of the damage. In particular resistive heating is consistently identified to cause a significant amount of the measured damage but does not completely explain all the physical damage witnessed. The discussed pressure loads including the acoustic and magnetic loads are not much studied but these effects are commonly suggested to explain variation in results or the difference between predicted and measured behaviour. Chemartin [9], Gineste [28] and Haigh [31] are some of the few authors to specifically investigate these loads in significant detail. These studies are thus discussed in detail in the following section. The purpose of this study, in contrast to these preceding works, is not to assess a single loading instant but to develop understanding on how the variation of pressure load magnitude and pressure load form influences material damage. With such a developed understanding it will then be possible for the first time to gauge how damage resulting from pressure compares with damage from other load types, e.g. thermalelectric loading, and thus its importance overall to material damage.

Table 2 Three damage areas as identified from experiment with a peak current is $40 \mathrm{kA}$, rise time from $10 \%$ to $90 \%$ of maximum current is $4 \mu \mathrm{s}$ and time through to $50 \%$ of maximum current is $20 \mu \mathrm{s}$

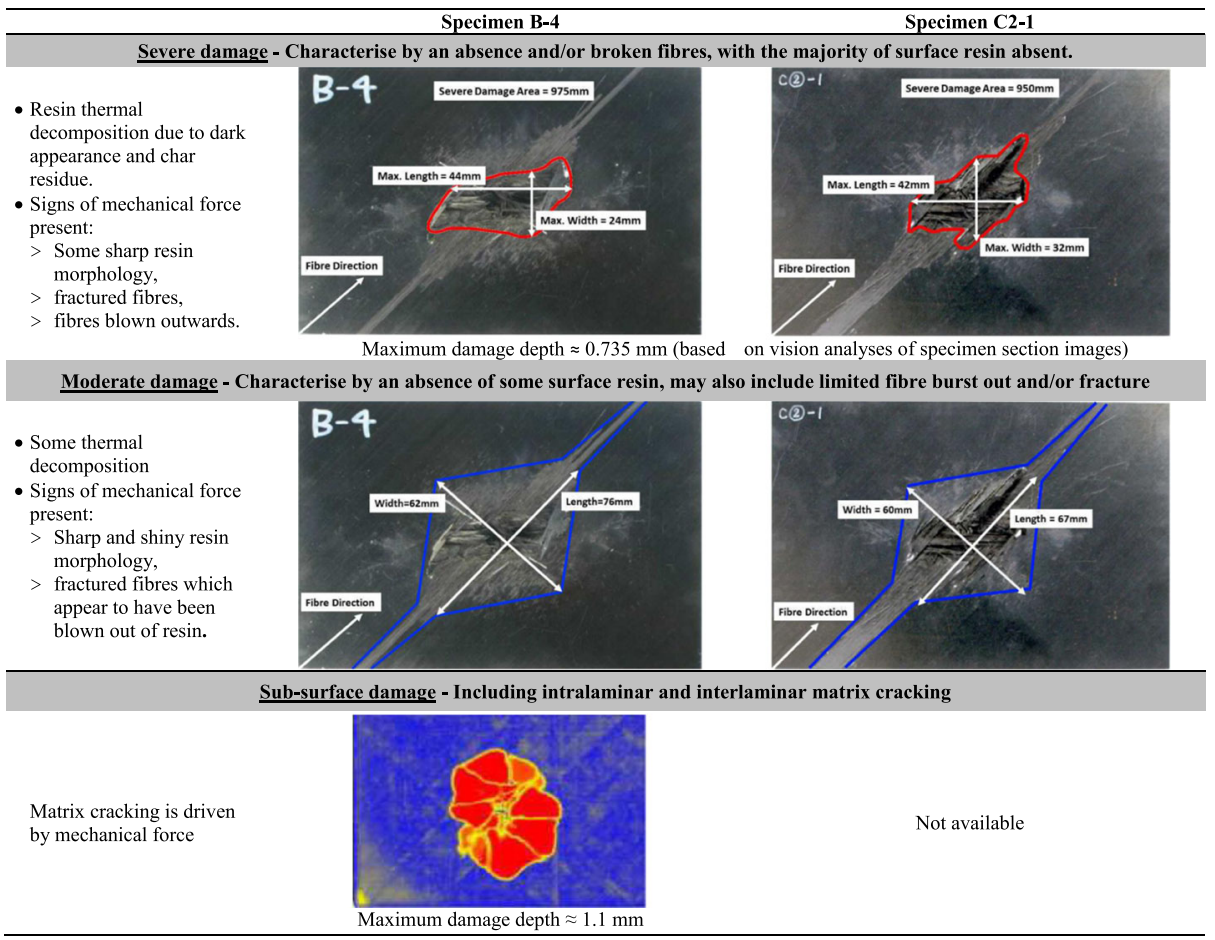




\section{Pressure Loading Phenomena}

Haigh [31] attempted to use special specimen holding fixtures and deflection measurement systems to differentiate experimentally between the impulse loading mechanisms during a simulated test. By striking the specimen directly and striking a metallic bar running above the specimen Haigh recorded equivalent peak deformations, concluding the acoustic load was the dominant loading mechanism. In addition when a lightning arc was configured to pass horizontally above the test setup the peak deformation measurement was more than double indicating the radial magnitude of the acoustic load was significantly greater than the longitudinal magnitude. It is important to note that in these experimental approaches specimen deformations with time is measured and not surface load. Two surface loads could result in equivalent global peak deformations but spread over significantly different areas these could create considerably different damage. Gineste et al. [28] again devises a specific test to characterize the acoustic load once more with a current flow tangentially to a PVC specimen and a displacement measurement system. In this case however a simulation model was used to reverse engineer the lightning strike's expansion wave to fit the displacement measurements. Gineste [28] states that the values calculated are of the same order of magnitude as those obtained for magnetic pressure as calculated by the theoretic analytic expression [34].

Chemartin et al. [9] observed, using Magnetohydrodynamics (MHD) simulations of the lightning arc plasma, that the Lorentz force and hence the magnetic load is concentrated at the centre of the arc, and reduces to zero at the edge of the arc resulting in a parabolic pressure load. Chemartin's combined experimental and simulations indicate that both the magnetic and fluid pressure must be taken into account to correctly calculate the specimen deflection during test. In conclusion Chemartin proposes the deflection of unpainted specimens (composite and aluminium) is primarily due to the acoustic load, while for painted specimen consideration of the magnetic pressure is required for realistic prediction of specimen deflection during test.

In addition to the experiments and simulations a number of the authors have also proposed pressure equations for the electromagnetic 'pinch' [9]. The proposed equations take the form of the electromagnetic pressure equation calculated from the momentum equation used in hydrodynamics [34]. The proposed equations are derived assuming the lightning arc is a perfect cylinder and the air has a fixed magnetic permeability. Equation (1) presents the generic form of the equation, where $i$ is the electric current and $\mu_{0}$ is the magnetic permeability constant of air and $r$ is the arc radius. It is worth noting that with this equation the magnitude of electromagnetic pinching pressure, $\nabla p$, will vary significantly depending on the current and the radius used.

$$
\nabla p=\mu_{0} i^{2} / 8 \pi^{2} r^{2}
$$

All authors [referenced in Table 3] fundamentally use the same equation; however, there are two significant differences in the proposed equations:

- The denominator numeral varies between authors, while the magnetic pressure equation stipulates that the factor of division is eight: Kawakami [13], Chemartin [9] and Haigh [24] use division factors of two, four and sixteen respectively.

- While all other authors have assumed a uniform pressure Chemartin [9], using simulations, has proposed a parabolic equation where the pressure at the arc centre is large and falls to zero at the edge of the arc radius. 
Table 3 Literature proposed lightning strike pressure loads

\begin{tabular}{|c|c|c|c|c|c|c|}
\hline & $\begin{array}{l}\text { Electromagnetic } \\
\text { 'Pinch' Equation }\end{array}$ & $\begin{array}{l}\text { Assumed } \\
\text { radius } \\
(\mathrm{mm})\end{array}$ & $\begin{array}{l}\text { Max } \\
\text { magnitude } \\
\text { for 40kA } \\
\text { strike (MPa) }\end{array}$ & $\begin{array}{l}\text { Max } \\
\text { magnitude } \\
\text { for } 200 \mathrm{kA} \\
\text { strike }(\mathrm{MPa})\end{array}$ & $\begin{array}{l}\text { Electromagnetic } \\
\text { 'Flux' equation }\end{array}$ & $\begin{array}{l}\text { Expansion } \\
\text { shock wave } \\
\text { magnitude } \\
(\mathrm{MPa})\end{array}$ \\
\hline Theoretical [34] & $\frac{\mu_{0} i^{2}}{8 \Omega^{2} R^{2}}$ & - & - & - & - & - \\
\hline Kawakami [18] & $\begin{array}{l}\frac{\mu_{0} i^{2}}{2 \pi^{2} R^{2}} \\
\end{array}$ & 1,2 & 25 & 637 & - & - \\
\hline Chemartin [9] & $\frac{\mu_{0} i^{2}}{4 \pi^{2} R^{2}}\left[1-\left(\frac{\mu_{0} i^{2}}{4 \pi^{2} R^{2}}\right)^{2}\right]$ & 5 & 2 & 50 & $\frac{\mu_{0} i^{2}}{4 \pi^{2} R^{2}}$ & - \\
\hline Munoz [17] & ${\frac{\mu_{0} i^{2}}{4 \pi^{2} R^{2}}}^{\mathrm{L}}$ & 5 & 2 & 50 & $\frac{\mu_{0} i^{2}}{4 \pi^{2} R^{2}}$ & 10 \\
\hline $\begin{array}{l}\text { Haigh [31], } \\
\quad \text { Gineste [28] }\end{array}$ & $\begin{array}{l}\frac{4 \pi^{2} R^{2}}{\mu_{0} i^{2}} \\
16 \pi^{2} R^{2}\end{array}$ & $4,5,6$ & 0.5 & 12.7 & $\begin{array}{l}4 \pi_{0} R^{2} \\
\frac{\mu_{0} i^{2}}{6 \pi^{2} R^{2}}\end{array}$ & 12.7 \\
\hline Reid [35] & $\propto \frac{i^{2}}{d^{2}}$ & - & - & 100 & - & 10 \\
\hline Hardwick [36] & - & - & - & 100 & - & 10 \\
\hline
\end{tabular}

In summary it is not possible to isolate the different proposed aspects of the pressure loads. Authors have until now used novel experimental setups and MHD simulations [37] to understand the loading pressure present during a test. Generally the literature suggests that pressure radically varies in time and magnitude. Table 3 summarises pressure loads proposed in the literature by each author along with the corresponding application radii. Theory is available to calculate the electromagnetic pinching pressure, however authors have modified this to match their experimental and simulation observations and incorporate the other pressure loads.

Rather than explicitly test each proposed load, the effect of varying pressure magnitudes and arc radii will first be investigated separately. The radius will be kept constant $(5 \mathrm{~mm}$, [9, $17,28,31]$ ) while investigating the effect of varying peak pressure magnitude (based on the magnitudes in the literature). These include the magnitude proposed for Hirano's current, both around the lower and upper limits, 2 and $50 \mathrm{MPa}$. Next the peak pressure load will be kept constant while the influence of the radius of loading will be investigated (1 to $5 \mathrm{~mm}$ - again covering the magnitudes proposed in the literature and documented in Table 3).

\section{Modelling}

Advances in numerical modelling techniques, including improved simulation of damage mechanics at micro and macro scale level, have enabled Finite Element methods to predict the damage response of impacted laminates with ever improving levels of accuracy [2-8]. Various failure criteria can be applied to predict the onset of fibre or matrix failure. Moreover post-initiation energy based or displacement based damage evolution models utilising principles of material degradation have been developed to predict damage progression. Using contact modelling methods to simulate cohesive behaviour at ply interfaces, the initiation and growth of delamination can be predicted from stress and energy based damage evolution and stiffness degradation models.

Herein the modelling approach used by Phadnis [3] and validated for transverse impact loads is used as an efficient, mature and robust approach. The Hashin failure criteria are used to predict intralaminar ply failure in the fibre direction accounting for fibre damage in 
compression and tension. This is also used for tensile failure in the directions transverse to the fibre direction were the matrix failure mode is dominant. However studies have shown that this approach struggles to accurately predict matrix compressive failure as greater direct transverse compressive stress will require greater shear stresses to cause matrix failure. An alternative matrix compressive failure model proposed by Puck is used instead. While this is proposed for the in-plane transverse direction, this failure model is also extended to the through thickness direction as this is also a matrix dominated direction. Delamination is modelled using the inbuilt cohesive surface option in ABAQUS/Explicit with an initial elastic region, initial failure and damage progression until ultimate failure. The bi-linear traction-separation relationship is used with failure initiation governed by the quadratic stress criterion. Delamination is propagated using the mixed-mode relationship proposed by Benzegagh and Kenane. Fracture toughness and the non-linearity coefficient have been experimentally determined in-house at Queen's University Belfast by Tan et al. [4] and interlaminar stiffness and strengths are referenced from the work of Rivallant et al. [38]. Table 4 presents the material constants modelled. This approach has been demonstrated to produce comparable predictions to measured experimental behaviour when coupled with appropriate model parameters for the material system, the specific crack location - stacking sequence combination and loading conditions. Demonstration is also available in the literature for a single set of delamination properties used to represent a range of crack location - stacking sequence combinations with resulting numerical predictions in good agreement with experimental measurements (e.g. Hongkarnjanakul et al. [39]).

Herein the focus will be on modelling a single preceding experimental setup [20] where the specimen is set on a copper plate which acts as an earth and the probe is 2 to $3 \mathrm{~mm}$ above the specimen hence the strike occurs near the specimen centre. Loading is thus applied about the specimen centre with the specimen simulated to be laid on top of the plate with material properties of copper. The copper plate is constrained from moving along the z-axis however the composite specimen is free to move. Due to the speed of the event and thus the inertial effects involved the analysis are solved using ABAQUS/Explicit. The modelled specimen is $150 \times 100 \mathrm{~mm}$ with a ply layup of $[45 / 0 /-45 / 90]_{4 \mathrm{~s}}$, matching the global dimensions and

Table 4 Model material properties

\begin{tabular}{ll}
\hline & Properties \\
\hline Elastic & $\mathrm{E}_{1}=130 \mathrm{GPa}$ \\
& $\mathrm{E}_{2}=\mathrm{E}_{3}=7.7 \mathrm{GPa}$ \\
& $\mathrm{G}_{12}=\mathrm{G}_{13}=4.8 \mathrm{GPa}$ \\
& $\mathrm{G}_{23}=3.8 \mathrm{GPa}$ \\
& $\gamma_{12}=v_{13}=0.3$ \\
& $v_{23}=0.35$ \\
& $\mathrm{X}_{\mathrm{T}}=2080 \mathrm{MPa}$ \\
& $\mathrm{X}_{\mathrm{C}}=1250 \mathrm{MPa}$ \\
& $\mathrm{Y}_{\mathrm{T}}=60 \mathrm{MPa}$ \\
& $\mathrm{Y}_{\mathrm{C}}=290 \mathrm{MPa}$ \\
& $\mathrm{S}_{12}=110 \mathrm{MPa}$ \\
& $\mathrm{k}=1 \times 10^{5} \mathrm{~N} / \mathrm{mm}{ }^{3}$ \\
& $\tau_{3}^{0}=20 \mathrm{MPa}$ \\
& $\tau_{s h}^{0}=36 \mathrm{MPa}$ \\
& $\mathrm{G}_{\mathrm{IC}}=0.5 \mathrm{~N} / \mathrm{mm}^{2}$ \\
& $\mathrm{G}_{\mathrm{IIC}}=1.6 \mathrm{~N} / \mathrm{mm}$ \\
& $\eta=1.45$ \\
\hline
\end{tabular}


laminate stacking sequence of the experimental specimens and enabling straight forward comparison between damage prediction and experimental damage measurement.

The key behaviour during the analysis is located mainly at the centre of the specimen therefore the mesh is refined at the centre and coarsens towards the specimen edges. A mesh convergence study initially considered an element size of $1.8 \mathrm{~mm}$ and one element for each ply thickness and C3D8R elements. The in-plane mesh seed was reduced by $0.3 \mathrm{~mm}$ each time and one element added to the number of elements through the thickness. Convergence was considered to have occurred with a mesh seed of $0.3 \mathrm{~mm}$ and 6 elements through the thickness of each ply. Figure 1 illustrates the final specimen mesh used in all analysis along with an overview of the analysis loading and boundary conditions.

\section{Results}

\subsection{General Description of Specimen Behaviour Under Load}

In order to understand behaviours in the composite specimen under loading the strains are initially presented as these are generally more easily interpreted in an orthotropic material. As this is an impact event a compressive pressure wave propagates through the material. The speed of the pressure wave is dependent on the bulk modulus and density of the material through which it propagates. Figure 2 illustrate typical through thickness strains (in the specimen axis system, $\varepsilon_{\mathrm{zz}}$ ) along the specimen centre line. The strains are plotted through the thickness of the specimen on the $\mathrm{x}$-axis, each curve represents a time step during the event. This exemplar considers a peak pressure load of $200 \mathrm{MPa}$ over a radius of $5 \mathrm{~mm}$ applied with a

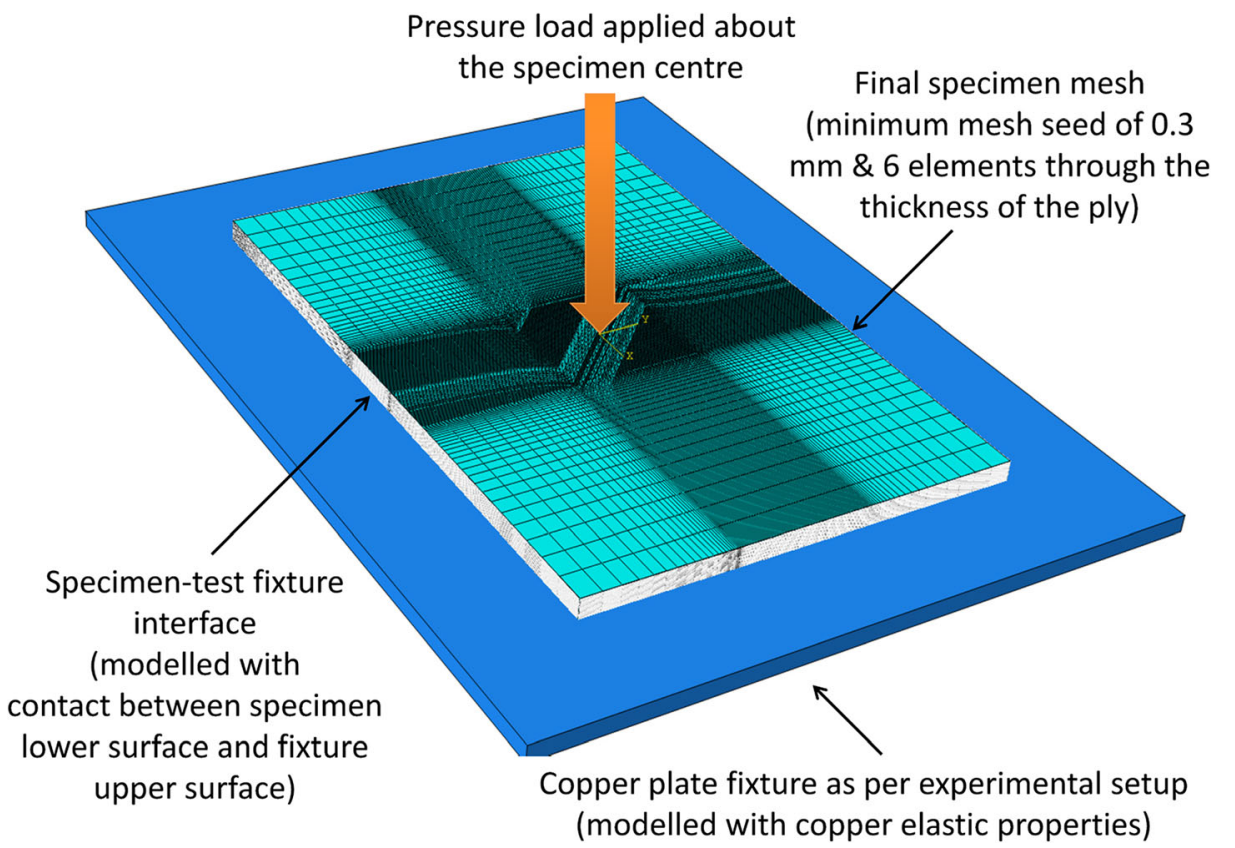

Fig. 1 Specimen mesh plus overview of analysis loading and boundary conditions 

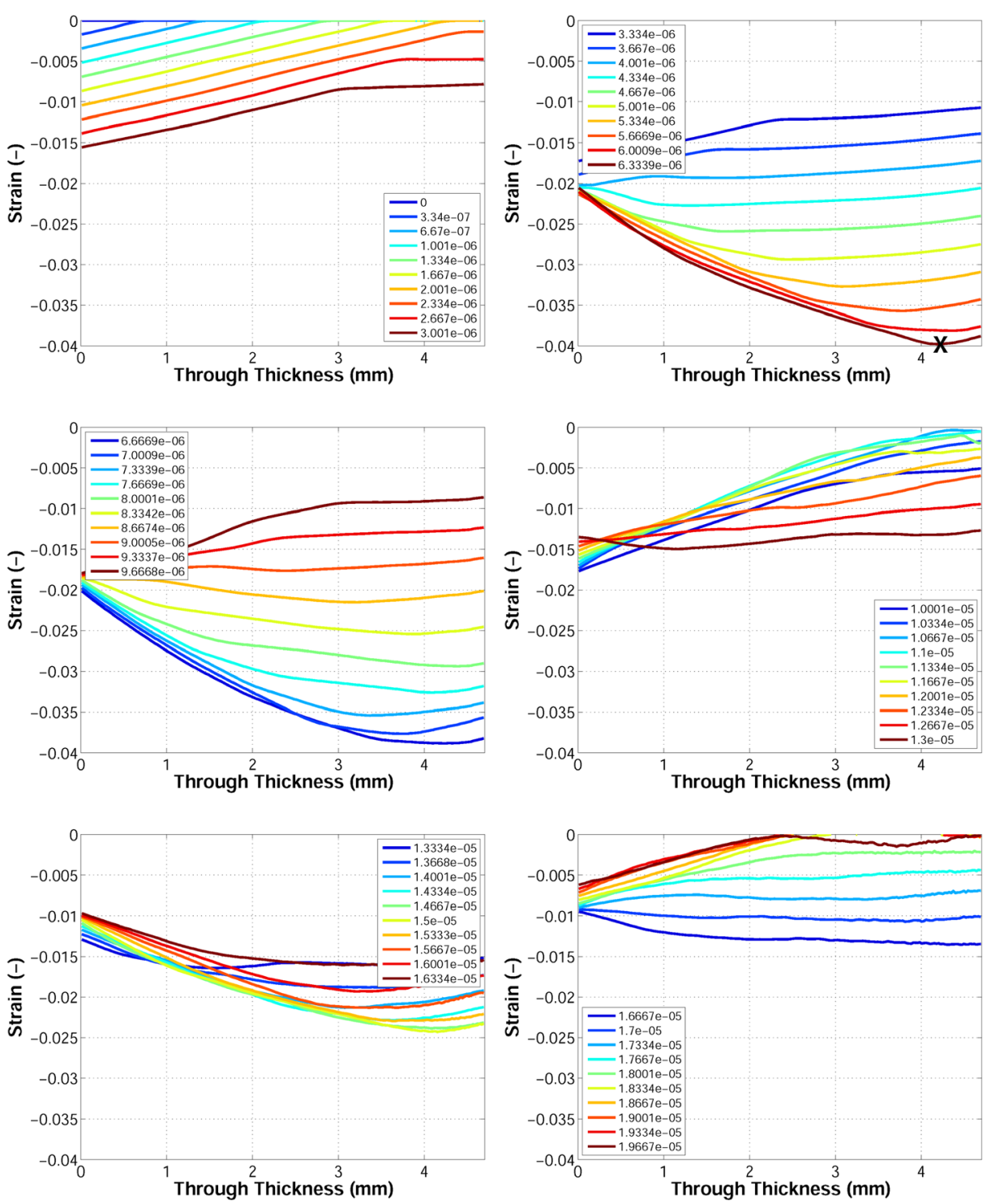

Fig. 2 Through thickness strain in the specimen axis system $\left(\varepsilon_{\mathrm{zz}}\right)$ through the thickness of the specimen at the centre element for sixty time steps from the beginning of the pressure loading to $20 \times 10-6$ s. X denotes the largest $\varepsilon_{\mathrm{zz}}$

time distribution corresponding to the current profile applied during the test (i.e. rise time from $10 \%$ to $90 \%$ of maximum pressure load is $4 \mu \mathrm{s}$ and time through to post-peak $50 \%$ of maximum pressure load is $20 \mu \mathrm{s})$.

Examining Fig. 2 it takes approximately $2.33 \times 10^{-6} \mathrm{~s}$ for the pressure wave to travel to the back face of the specimen. In general a compressive through thickness strain with a gentle gradient is thus present throughout the specimen thickness soon after the pressure load is applied. The largest strains occur in the through thickness direction with a maximum reached close to the back face of the plate after $6.3 \times 10^{-6} \mathrm{~s}$ (X marked in Fig. 2). This is due to the 
combination of the reflected strain wave meeting the oncoming strain wave. The strain at the front surface peaks at a lower magnitude and before the back surface strain peak, approximately occurring around the time of the peak pressure load. Overall the magnitude of the through thickness strain oscillates as the pressure wave reflects off the back and front face of the specimen. The maximum strains occurring are at the plate centre and through the plate thickness due to the localised nature of the loading.

In-plane strains are also generated as the pressure load is localised and causes plate bending. The predicted in-plane strains are similar in form and magnitude (in the specimen axis system, $\varepsilon_{\mathrm{xx}}$ and $\left.\varepsilon_{\mathrm{yy}}\right)$ with Fig. 3 presenting representative in-plane strains $\left(\varepsilon_{\mathrm{xx}}\right)$ along the specimen centre line. The in-plane strain through the plate thickness is not a smooth curve but has step changes from one ply to the next due to the varying ply orientations and stiffness. The maximum compressive or tensile in-plane strains are significantly smaller in magnitude (by a factor of 24 in this exemplar) than the through thickness strains. Compressive in-plane strain occurs within a zone at the top of the specimen with tensile strains below this and through to the back face. Again the maximum strains occur at the plate centre and the magnitude of the strains oscillates as the pressure wave reflects off the specimen back and front faces. As with the in-plane strains the shear strains (in the specimen axis system, $\varepsilon_{\mathrm{xz}}$ ) are smaller in magnitude than the through thickness strains, Fig. 4. The peak shear strain is equivalent in magnitude to the peak in-plane strain but occurs at the back face of the specimen approximately $8.67 \times 10^{-6} \mathrm{~s}$ after the pressure load initiation ( $\mathrm{X}$ marked in Fig. 4).

\subsection{Influence of Pressure Magnitude (Constant Radius of $5 \mathrm{~mm}$, Varying Peak Load)}

The profile of the strain wave for varying pressure magnitudes is similar in all cases and the behaviour discussed in detail in Section 5.1 remains the same, only the magnitude of strain (and thus stress) changes significantly with increasing peak pressure load. Table 5 summarises the maximum through-thickness and in-plane stresses (in the local ply material axis) predicted during four analysis with peak pressure loads between 2 and $400 \mathrm{MPa}$. In general for the case where the radius is held constant there is a linear relationship between the peak pressure load and the maximum through-thickness and in-plane stresses.

\subsubsection{Intralaminar Failure}

The Hashin fibre failure, Hashin matrix tensile failure criteria and Puck matrix compressive failure criteria were initially applied to these analyses through a user subroutine. Only matrix compressive failure is predicted to occur in the cases when a peak pressure loading of $200 \&$ $400 \mathrm{MPa}$ was applied. Figure 5 illustrates the predicted damage area for the $200 \mathrm{MPa}$ peak pressure load case. When viewed from the back surface the damage shape is circular with a radius of failure of $4.65 \mathrm{~mm}$. Figure 6 plots the critical failure index and relevant stress magnitudes along the specimen centre line during the time period of predicted failure. The through-thickness compressive stress wave is initially below a critical magnitude but once the wave reflects off the back surface a critical through-thickness stress is reached and failure is predicted. In this case (200 MPa peak load) the fibre compression failure index only reached 0.05 at the loaded surface, the in-plane transverse matrix tensile index reached no more than 0.025 near the back surface and the through thickness matrix tensile index peaks at less than 0.15 , again towards the back surface. This type of damage is 

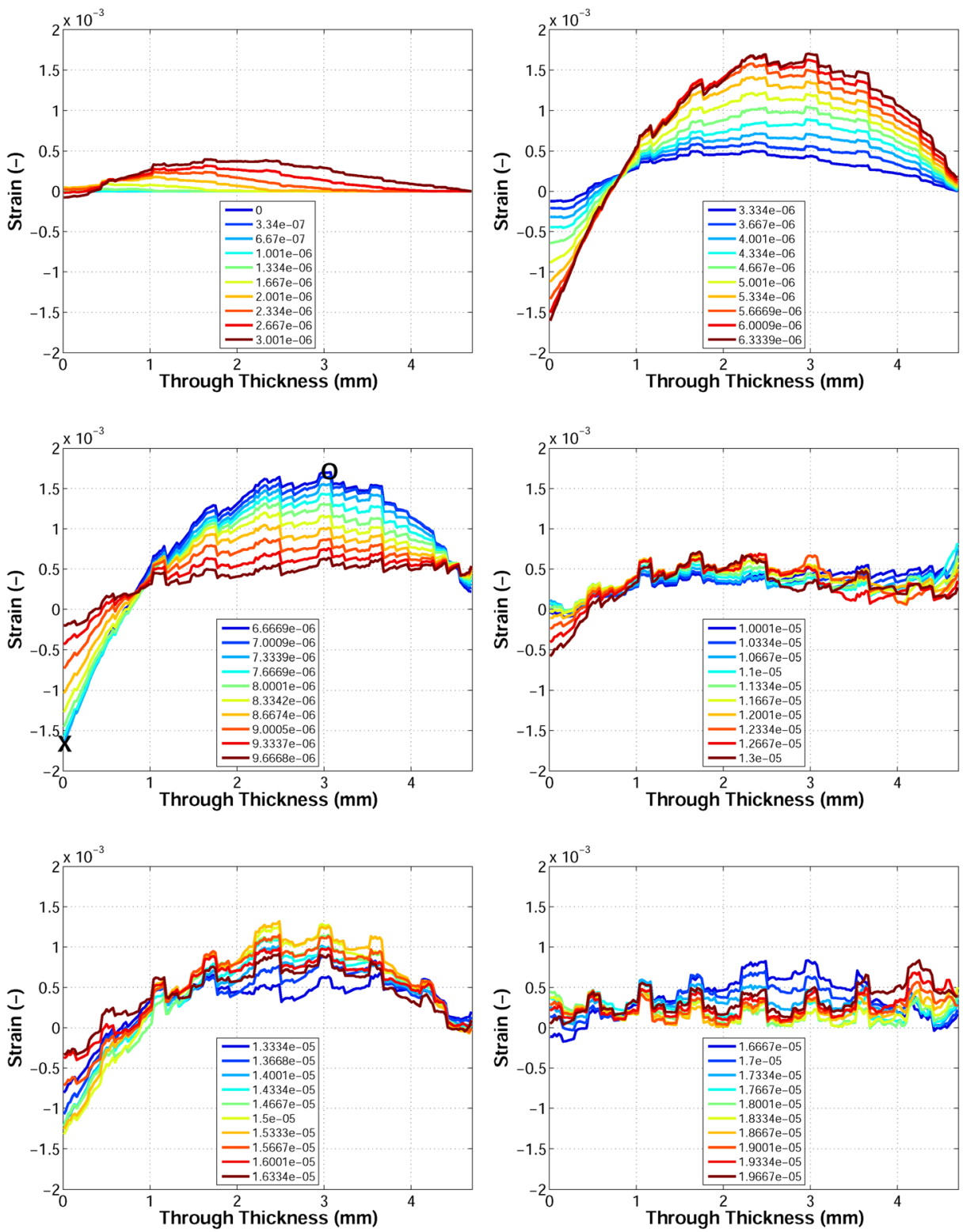

Fig. 3 In-plane strain in the specimen axis system $\left(\varepsilon_{x x}\right)$ through the thickness of the specimen at the centre element for sixty time steps from the beginning of the pressure loading to $20 \times 10^{-6} \mathrm{~s}$. O and $\mathrm{X}$ denotes the largest $\varepsilon_{\mathrm{xx}}$

similar to previous experimental work where damage occurs at the back face due to transverse low velocity impact loading [2, 4].

In all these simulation cases (with a constant radius and pressure waveform) the dominant lamina stress which causes failure is $\sigma_{33}$, while the in-plane stress, $\sigma_{11}$ and the through-thickness shear stress, $\sigma_{13}$ have a negligible contribution. Moreover the simulation results demonstrate a linear relationship exists between the applied peak pressure load and the maximum through-thickness 

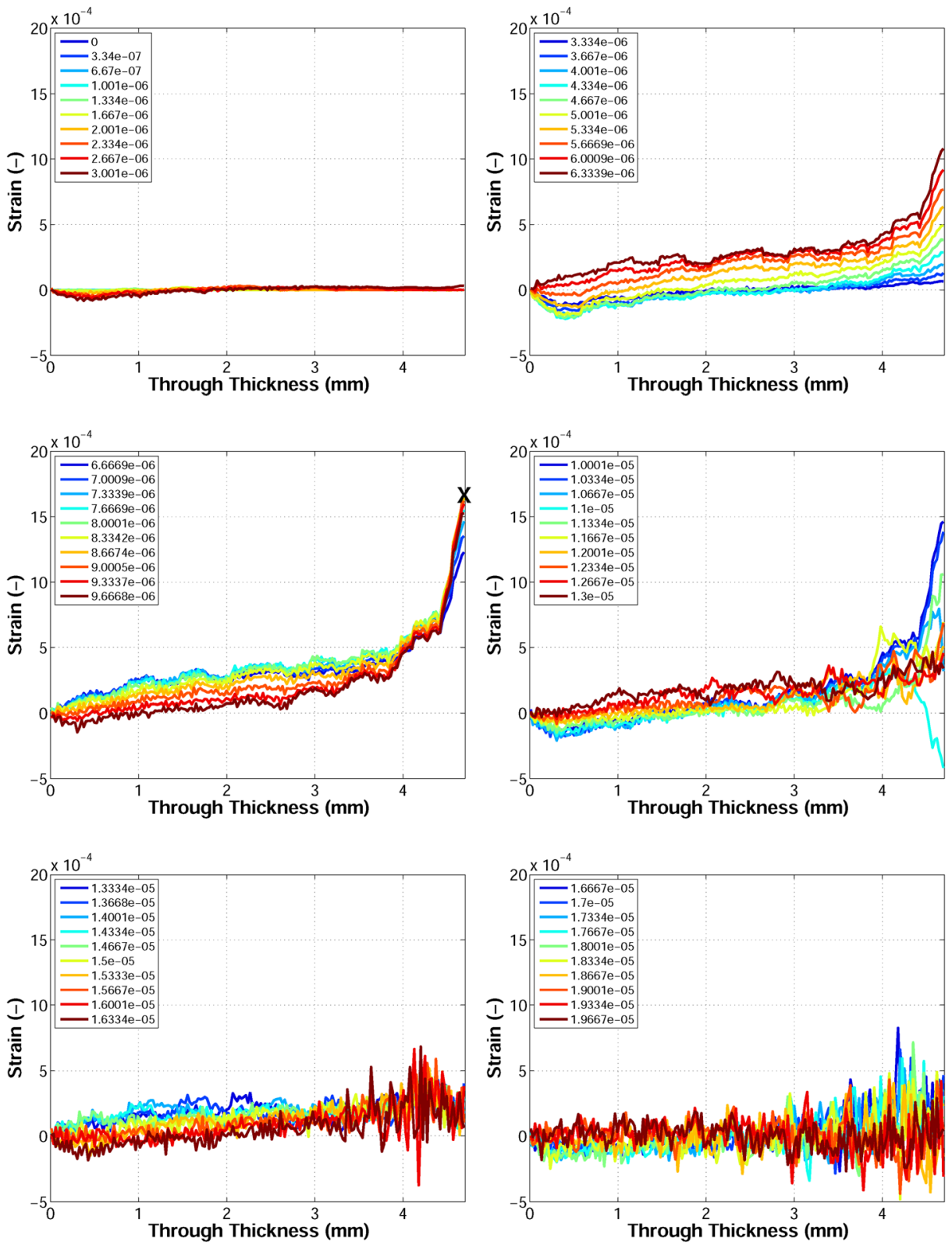

Fig. 4 Shear strain in the specimen axis system $\left(\varepsilon_{\mathrm{xz}}\right)$ through the thickness of the specimen at the centre element for sixty time steps from the beginning of the pressure loading to $20 \times 10^{-6} \mathrm{~s}$. X denotes the largest $\varepsilon_{\mathrm{xz}}$

stress, Table 5, and therefore the maximum stresses for any peak pressure load can be estimated. If we then simplify the Puck matrix compressive failure criteria to a one dimensional stress failure criteria in the through-thickness direction it is possible to calculate the minimum applied peak pressure load (with a fixed radius of $5 \mathrm{~mm}$ ) which will be sufficient to cause damage, $-167.5 \mathrm{MPa}$.

The damage through the composite specimen increases with increasing peak pressure magnitude until damage is present throughout the thickness of the specimen. In the case of 
Table 5 Maximum predicted stress in the local ply material axis with constant radius of $5 \mathrm{~mm}$, peak loads 2, 50, 200, $400 \mathrm{MPa}$

\begin{tabular}{llll}
\hline $\begin{array}{l}\text { Peak pressure } \\
\text { loads }\end{array}$ & $\begin{array}{l}\text { Maximum through- } \\
\text { thickness stress } \sigma_{33}\end{array}$ & $\begin{array}{l}\text { Maximum in- } \\
\text { plane stress } \sigma_{11}\end{array}$ & $\begin{array}{l}\text { Maximum in- } \\
\text { plane stress } \sigma_{22}\end{array}$ \\
\hline $2 \mathrm{MPa}$ & -3.7 & -3.5 & -1.3 \\
$50 \mathrm{MPa}$ & -88.4 & -78.9 & -30.4 \\
$200 \mathrm{MPa}$ & -346.9 & -291.5 & -119.3 \\
$400 \mathrm{MPa}$ & -692.2 & -536.9 & -238.7 \\
\hline
\end{tabular}

a peak pressure load of $400 \mathrm{MPa}$ the damage at the surface of the composite specimen is $6 \mathrm{~mm}$, with a damage area of radius $8.4 \mathrm{~mm}$ on the bottom surface. In this case due to the magnitude of the applied pressure load, the material fails when the initial stress wave initially propagates through the specimen and therefore failure begins from the top of the plate and propagates down through the plate thickness. Whereas with smaller peak magnitudes, failure begins from the back surface and propagates upwards through the plate thickness. In both cases matrix cracking is predicted by the Puck criteria (as outlined in the Modelling Section, Section 4).

\subsubsection{Interlaminar Failure}

Delamination initiation occurs in the load cases with peak pressure loads of $200 \mathrm{MPa}$ and above, Table 6. The largest delamination damage variable reached is 0.9 under the $400 \mathrm{MPa}$ loading. Table 6 also records the location of delamination initiation. Under the $200 \mathrm{MPa}$ load the delamination initiation is found to occur in the region beneath the applied load and after the
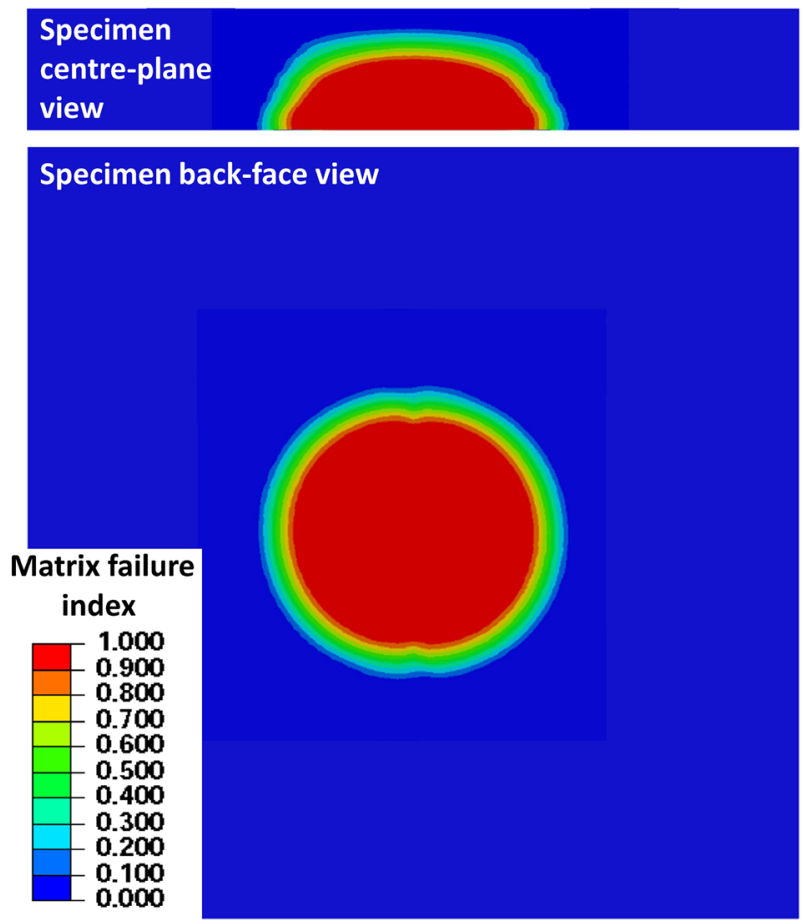

Fig. 5 Compressive through-thickness matrix failure index under a peak pressure load of $200 \mathrm{MPa}$ and load radius of $5 \mathrm{~mm}$ (central $30 \times 30 \mathrm{~mm}$ of specimen) 

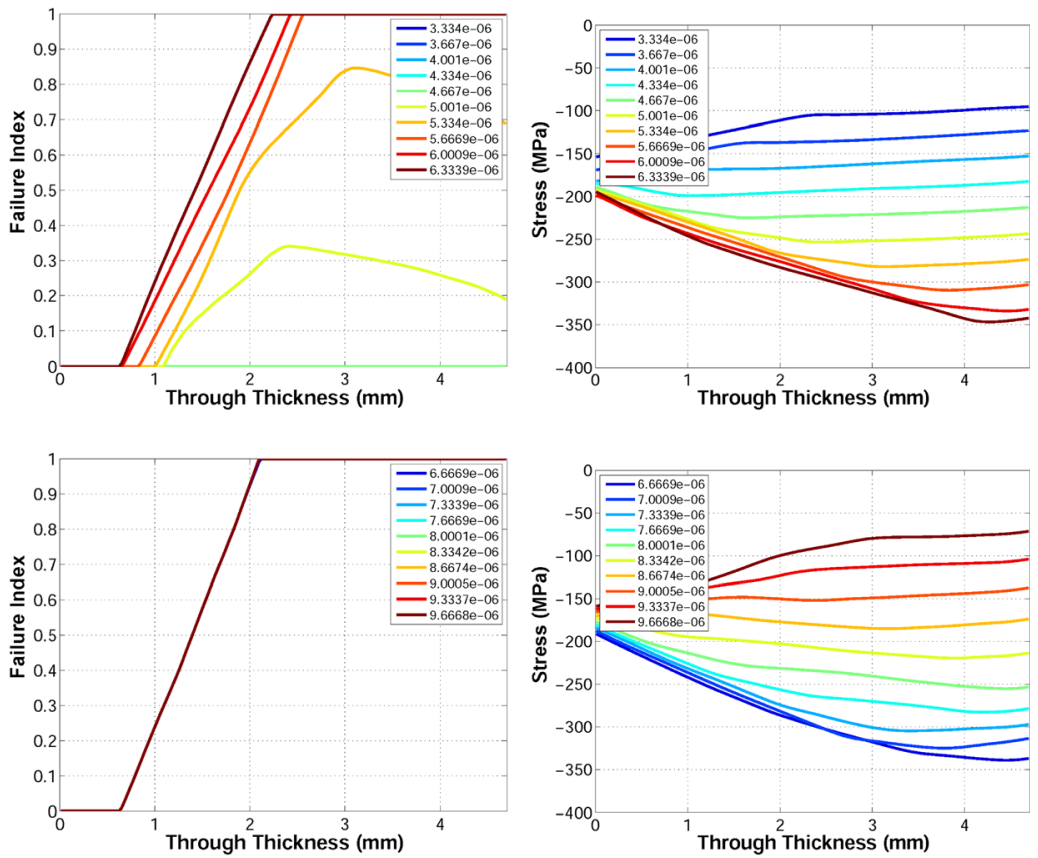

a)

b)
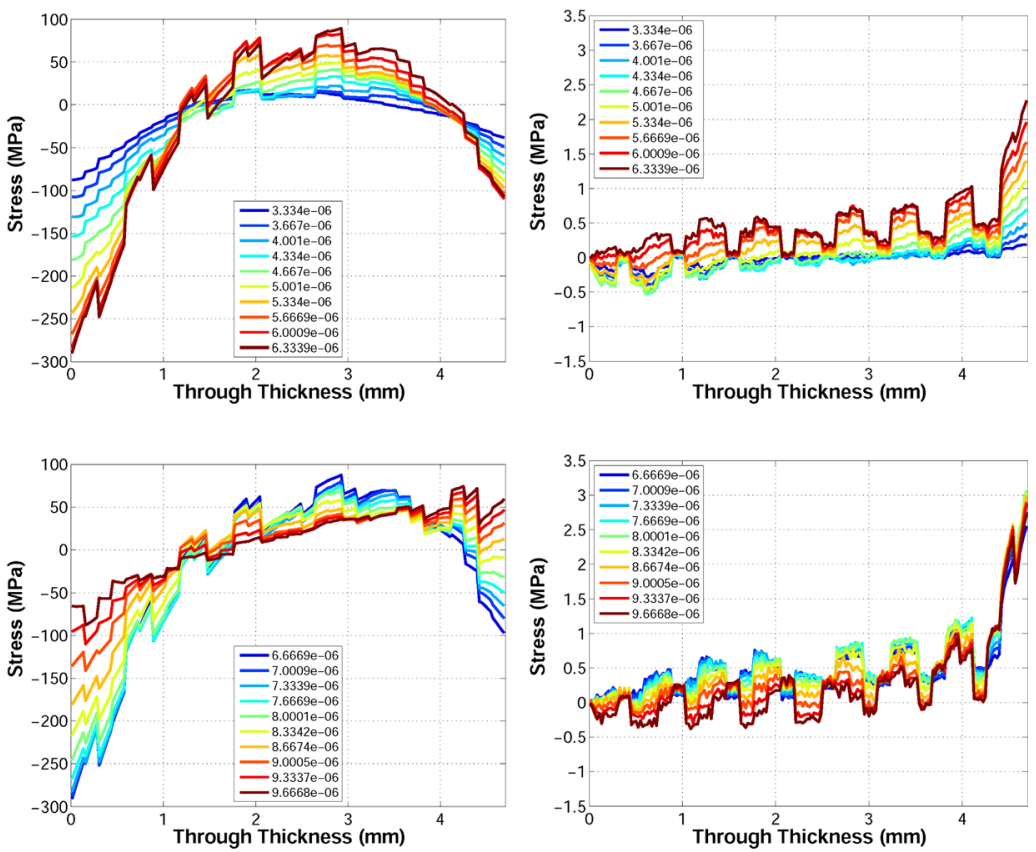

c)

d)

Fig. 6 Through thickness compressive failure index and relevant stresses between $3.3 \times 10^{-6}$ and $9.7 \times 10^{-6} \mathrm{~s}$ with a peak pressure load of $200 \mathrm{MPa}$ and a $5 \mathrm{~mm}$ loading radius: a) Through thickness compressive failure index, b) $\sigma_{33}$, c) $\sigma_{11}$, d) $\sigma_{13}$ (all in the local ply material axis) 
Table 6 Predicted delamination initiation with constant radius of $5 \mathrm{~mm}$, peak loads 50, 200 and $400 \mathrm{MPa}$

\begin{tabular}{|c|c|c|c|c|}
\hline Peak pressure loads & $\begin{array}{l}\text { Maximum radii of } \\
\text { delamination } \\
\text { initiation }(\mathrm{mm})\end{array}$ & $\begin{array}{c}\text { Maximum } \\
\text { delamination } \\
\text { damage variable }\end{array}$ & $\begin{array}{c}\text { Delamination } \\
\text { through thickness } \\
\text { location }\end{array}$ & $\begin{array}{l}\text { Delamination } \\
\text { initiation form }\end{array}$ \\
\hline $50 \mathrm{MPa}$ & - & - & - & - \\
\hline $200 \mathrm{MPa}$ & 3.5 & 0.39 & $\begin{array}{c}\text { Close to the } \\
\text { specimen back face }\end{array}$ & $\begin{array}{l}\text { Circular shaped } \\
\text { beneath load } \\
\text { application region }\end{array}$ \\
\hline $400 \mathrm{MPa}$ & 14 & 0.90 & Throughout thickness & $\begin{array}{l}\text { Circular shaped } \\
\text { beneath load } \\
\text { application region at } \\
\text { the back face \& } \\
\text { Donut shaped around } \\
\text { load application } \\
\text { region at the loaded } \\
\text { face }\end{array}$ \\
\hline \multicolumn{5}{|c|}{ Example of delamination initiation in plate cross-section: peak load of $200 \mathrm{MPa}$ and load radius of $5 \mathrm{~mm}$} \\
\hline
\end{tabular}

time when the peak pressure load is applied. The pressure load initially compresses the specimen however as the pressure load reduces the composite specimen springs back and away from the copper plate below. Due to spring back, bending occurs in the back surface causing delamination initiation. In the $400 \mathrm{MPa}$ case, initiation occurs throughout the thickness of the specimen. Delamination initiation in the top half of the specimen was found to occur early in the analysis due to local deformations at the region of the area under the pressure load. Whereas delamination initiation in the bottom half of the specimen again was found to occur in the region beneath the applied load due to specimen spring back and resulting bending.

Although the employed modelling approach represents a standard method a number of caveats should be considered along with the predictions. In all cases inter and intra lamina damage has been predicted in the immediate vicinity of each other. The modelling strategy employed does not represent interaction between matrix cracking and delamination. Alternative approaches have been proposed to model interaction, e.g. [40, 41], but such models are beyond the scope of this work. In addition delamination initiation is predicted to occur between multiple ply orientations. Although only delamination initiation is predicted care is required with these predictions as the modelled BK material properties are not fully generic and best represent delamination between the plies of a unidirectional laminate. Finally, although Puck's criterion is widely used for the prediction of matrix-dominated damage it does not account robustly for in-situ effects (i.e. where the effective shear strength of a ply may be shown to increase when embedded in a multidirectional laminate [4]). Once more advanced techniques have been demonstrated to represent such in-situ effects, Catalanotti et al. [42], but again such modelling is beyond the focus of this work.

\subsection{Influence of Pressure Radius (Constant Peak Pressure Load 200 MPa, Varying Radius)}

Figures 7 and 8 shows the development of in-plane and through-thickness strains for three loading radius cases $(5,3$ and $1 \mathrm{~mm})$. The developed strain patterns are similar in form to the 


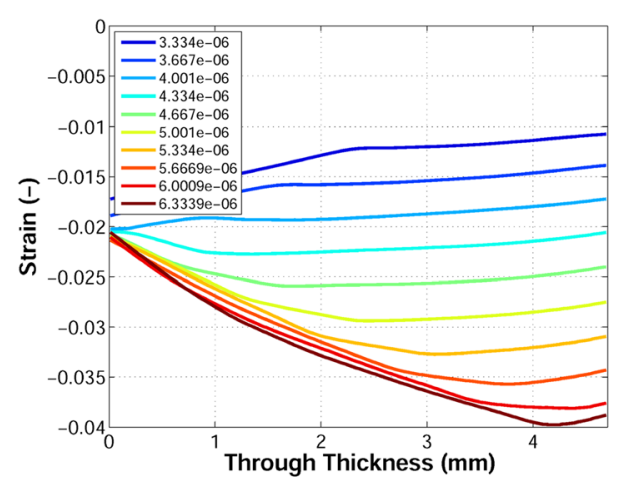

a)

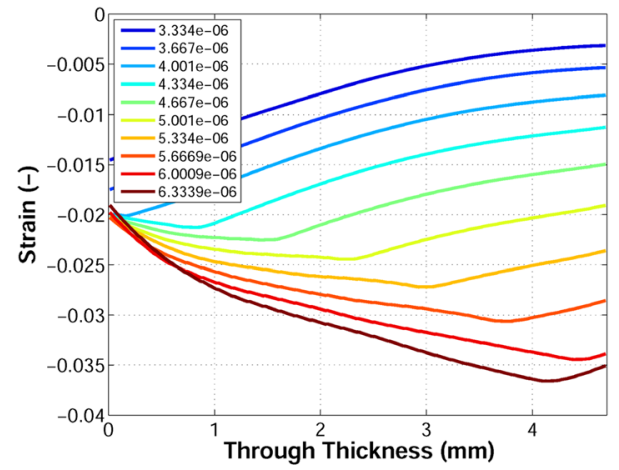

b)

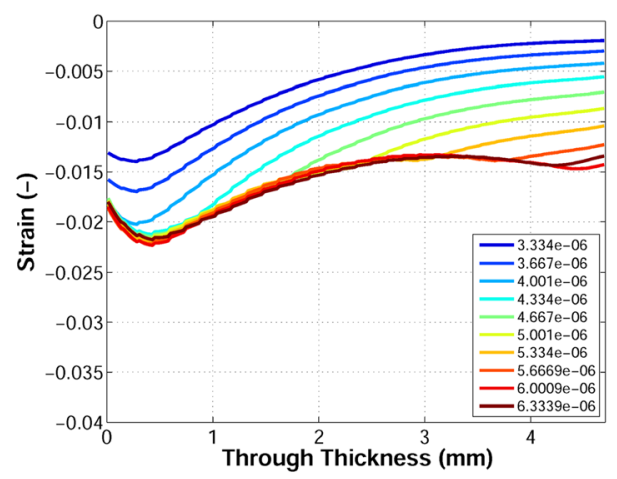

c)

Fig. 7 Through thickness strain $\left(\varepsilon_{33}\right)$ through the thickness of the specimen at the centre element for three radii, a $5 \mathrm{~mm}$, b $3 \mathrm{~mm}$, c $1 \mathrm{~mm}$

previous results presented and discussed in Section 5.1. In this case the peak strain magnitudes vary with radius. This is because the same pressure magnitude is being applied but over different areas, which results in different mass disturbance over time and thus varying pressure wave momentum. Moreover as the same pressure is applied over varying areas the resultant local bending and deformation gradients change which generally produces larger stresses and strains locally to the loaded surface. Thus as the radius of loading is reduced the peak in-plane strain $\left(\varepsilon_{11}\right)$ increases (at the loaded surface). However the pressure wave does not propagate through the thickness with the same energy when the radius of loading is decreased. Thus the peak through thickness strain $\left(\varepsilon_{33}\right)$ occurs closer to the loaded surface and its magnitude is smaller, Fig. 7.

\subsubsection{Intralaminar Failure}

As in the first study the only mode of failure is compressive through-thickness matrix failure which occurs with loading radii of 5 and $3 \mathrm{~mm}$ at the back surface of the composite. For both radii, the failure area is again semi-circular in shape when viewed in cross-section and circular when viewed from the back surface. Under a load radii of $1 \mathrm{~mm}$ intralaminar damage does not occur in the plate but, more significantly, the peak stress in the plate occurs close to the top surface of the specimen as the stress wave does not propagate through the plate. 


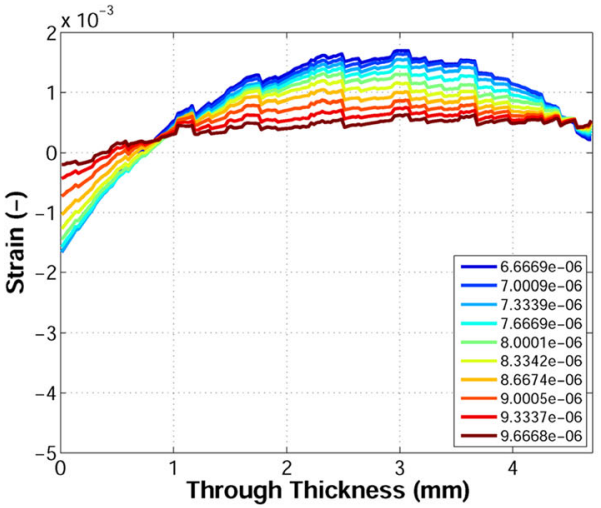

a)

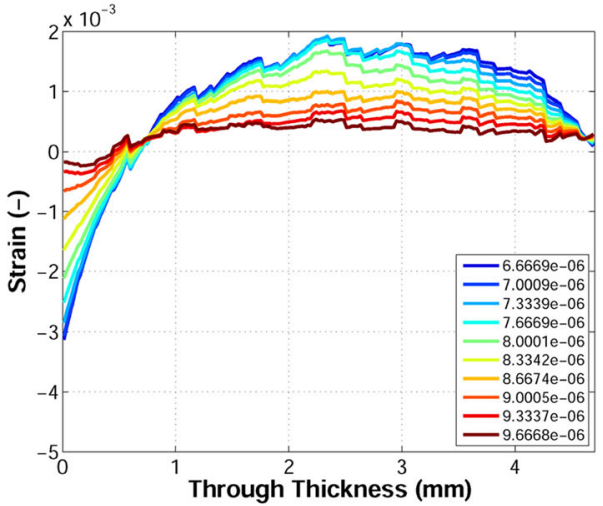

b)

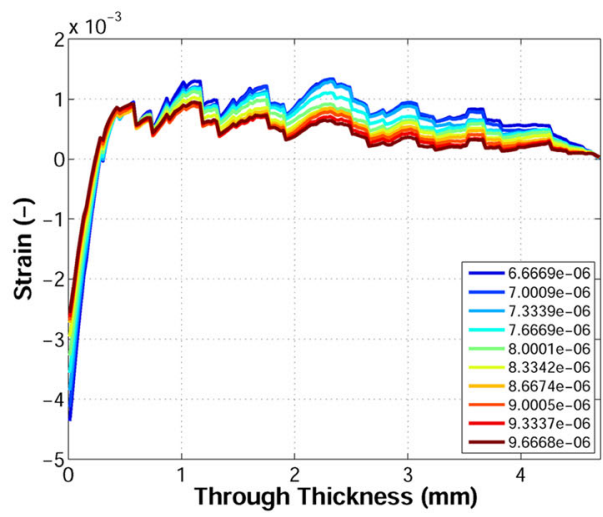

c)

Fig. 8 In-plane strain $\left(\varepsilon_{11}\right)$ through the thickness of the specimen at the centre element for three radii, a $5 \mathrm{~mm}, \mathbf{b}$ $3 \mathrm{~mm}$, c $1 \mathrm{~mm}$

Table 7 Predicted delamination initiation with constant peak load of $200 \mathrm{MPa}$, load radii 1, 3, and $5 \mathrm{~mm}$

\begin{tabular}{|c|c|c|c|c|}
\hline $\begin{array}{l}\text { Load radius } \\
\quad(\mathbf{m m})\end{array}$ & $\begin{array}{c}\text { Maximum radii of } \\
\text { delamination } \\
\text { initiation }(\mathbf{m m})\end{array}$ & $\begin{array}{c}\text { Maximum } \\
\text { delamination } \\
\text { damage variable }\end{array}$ & $\begin{array}{c}\text { Delamination } \\
\text { through thickness } \\
\text { location }\end{array}$ & $\begin{array}{l}\text { Delamination } \\
\text { initiation form }\end{array}$ \\
\hline 1 & 2.5 & 0.23 & $\begin{array}{l}\text { Close to the loaded } \\
\text { face }\end{array}$ & $\begin{array}{c}\text { Donut shaped around } \\
\text { load application } \\
\text { region }\end{array}$ \\
\hline 3 & 5 & 0.15 & $\begin{array}{l}\text { Close to the loaded } \\
\text { face }\end{array}$ & $\begin{array}{c}\text { Donut shaped around } \\
\text { load application } \\
\text { region }\end{array}$ \\
\hline 5 & 2 & 0.39 & $\begin{array}{l}\text { Close to the } \\
\text { specimen back face }\end{array}$ & $\begin{array}{l}\text { Circular shaped } \\
\text { beneath load } \\
\text { application region }\end{array}$ \\
\hline \multicolumn{5}{|c|}{ Example of delamination initiation in plate cross-section: load radius of $1 \mathrm{~mm}$ and peak load of 200MPa } \\
\hline
\end{tabular}




\subsubsection{Interlaminar Failure}

Delamination initiation is predicted in all three cases but complete delamination is not predicted, Table 7 . Under the 1 and $3 \mathrm{~mm}$ radius loading conditions delamination initiation is predicted in the top half of the specimen, as a donut shape surrounding the loading region. Under the $5 \mathrm{~mm}$ load radius delamination initiation is found to occur in the bottom half of the specimen in a region beneath the applied load. As before the mechanisms which lead to damage are the local deformation at the boundary of the applied loads with smaller loading radii $(1 \& 3 \mathrm{~mm})$ and spring back induced bending with the larger loading radius $(5 \mathrm{~mm})$.

\subsection{Comparison with Experimental Results}

As defined in Section 2 experimental measurements for the modelled test setup report no damage towards the back face, with severe and delamination damage measured only within depths of $0.735 \mathrm{~mm}$ and $1.1 \mathrm{~mm}$ from the loaded surface (Table 2). Based on the simulations presented thus far this is only possible if:

- the peak pressure is greater than that required to cause through-thickness matrix compressive failure,

- the radius of loading is sufficiently small so that the pressure wave weakens as it propagates through the thickness of the specimen.

Therefore a pressure wave which causes this type of damage will overwhelm the material upon the initial loading but will not propagate through the plate. If the peak pressure magnitude or radius is too small no damage occurs or if they are too large then damage occurs

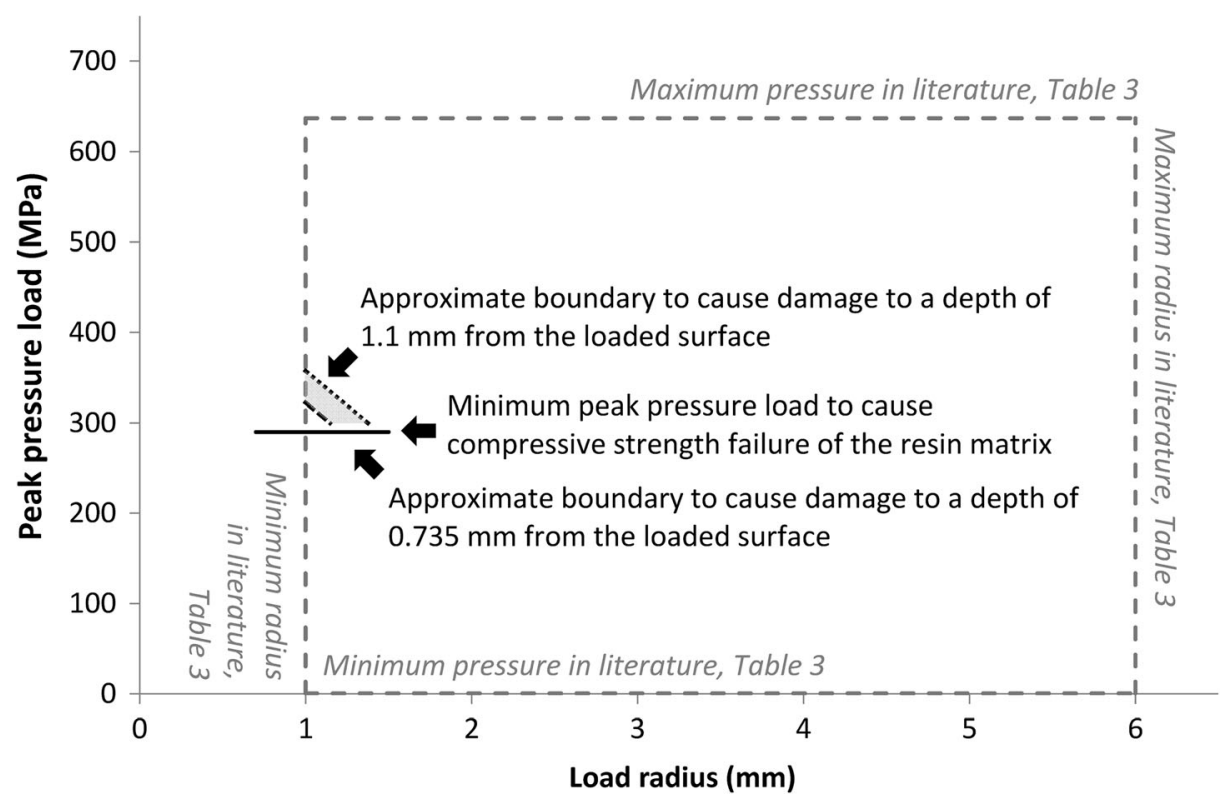

Fig. 9 Map of load combinations (peak pressure load magnitude, loading application radius) which predict a damage depth within the experimentally measured envelope 
through the plate thickness. Reconsidering the preceding six simulations only the $1 \mathrm{~mm}$ radius loading condition resulted in a stress wave such that the peak stresses occurred close to the top surface. Focusing on these simulation conditions and the two depths of measured lightning damage it is possible to refine the critical peak pressure magnitude and loading radius.

Holding the loading radius constant at $1 \mathrm{~mm}$ and varying the peak pressure magnitude the simulation model can predict the pressure to cause damage to the depths measured experimentally (Table 2). Repeating the same process but varying the load radius and holding the peak pressure load constant at $300 \mathrm{MPa}$, a series of points representing loading conditions which recreate the experimental damage depth can be found. Assuming a simple linear relationship, given the small changes in peak pressure load and loading radius, a number of approximate boundaries can be defined on the loading conditions required to recreate the experimental behaviour, Fig. 9. Examining Fig. 9 it is clear that the loading conditions to reproduce the measured damage behaviour are very specific, particularly considering the significant difference in damage depth (50\%). The load radii and peak pressure magnitudes proposed in previous works are significantly broader. In particular most authors propose
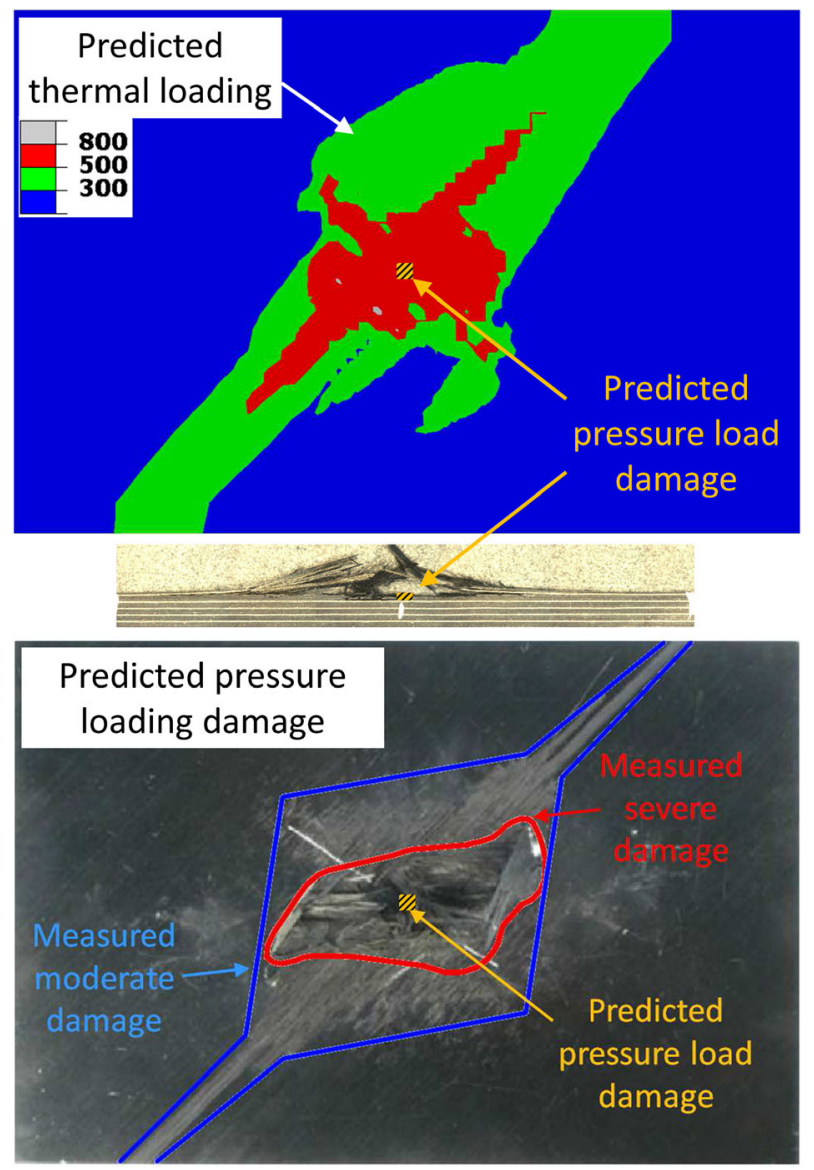

Fig. 10 Predicted damage due to pressure load (Peak pressure load of $322 \mathrm{MPa}$, loading radius of $1 \mathrm{~mm}$ ) overlaid on experimentally measured damage plus a thermal loading distribution predicted by a typical thermalelectric analysis 
a constant arc channel radius around $5 \mathrm{~mm}$ however some authors also propose a concentration of the electrical current at the centre of the channel thus the arc radius could effectively be smaller. However, it is important at this stage to consider other loading mechanisms which are present during lightning strikes which are known to induce surface damage.

Thus finally it is appropriate to compare the damage caused by pressure loading along with damage resulting from thermal-electric predictions [43] and the experimental results, Fig. 10 Examining Fig. 10 it is evident that the damage due to the pressure load is a small proportion of that measured experimentally ( $\approx 1 \%$ of the severe damage area). Also overlaid in Fig. 10 is a thermal loading distribution predicted by a typical thermal-electric analysis [43]. Again the pressure load induced damage area is orders of magnitude smaller than the temperature zones which would cause damage to the composite material. Together these results suggest that the pressure loads, as previously described in the literature, are unlikely to contribute significantly to specimen damage.

\section{Conclusions}

A simulation study has been undertaken to examine the proposed lightning strike pressure shockwave loads from the literature using a well-established modelling approach for composite damage prediction. The simulations have demonstrated the relationships between the magnitude of the applied pressure, the radius the pressure is loaded over and the internal composite strains and damage behaviour. From the simulations the magnitude of the strain fields and damage behaviour depends on the pressure magnitude but the internal strain waves are not fundamentally changed with this variable. When the radius of loading is varied this influences both the shape and the magnitude of the strains and thus damage behaviour. The arc radius and shock wave pressure required to cause the type of damage witnessed experimentally represents a small sub-set of the broad range of values proposed in the literature. Given the constraining requirement to only cause damage to the top surface of a specimen and the demonstrated sensitivity of throughthickness compressive stress to the modelled arc channel radius it can be considered unlikely that these conditions are met during each lightning strike test. Moreover the maximum predicted damage radius from simulations (considering both intralaminar and interlaminar damage) is negligible with respect to that measured experimentally. Thus shock wave pressure loading can only be responsible for a small component of the mechanical induced damage witnessed in specimens subjected to lightning strike testing. Based on the results herein electrical loading (and resulting resistive heating) is a significantly greater source of damage than pressure shockwave loading when each loading mechanism is considered in isolation. Given the significant mechanical damage reported experimentally mechanical behaviours associated with resistive heating, such as thermal expansion, and the interaction of loading mechanisms (mechanical and thermalelectric) require greater study to fully understand the damage formation. It is worth reflecting that the simulations represent laboratory test conditions and although there are no scale effects between the simulation and the test arrangement there will be variation between the test environment and test boundary conditions and real world lightning strike events. Thus future work should also establish the sensitivity of damage prediction to the modelled test conditions. 
Open Access This article is distributed under the terms of the Creative Commons Attribution 4.0 International License (http://creativecommons.org/licenses/by/4.0/), which permits unrestricted use, distribution, and reproduction in any medium, provided you give appropriate credit to the original author(s) and the source, provide a link to the Creative Commons license, and indicate if changes were made.

\section{References}

1. Dong, Q., Wan, G., Xu, Y., Guo, Y., Du, T., Yi, X., Jia, Y.: Lightning damage of carbon Fiber/epoxy laminates with interlayers modified by nickel-coated multi-walled carbon nanotubes. Appl. Compos. Mater. 24(6), 1339-1351 (2017)

2. Shi, Y., Swait, T., Soutis, C.: Modelling damage evolution in composite laminates subjected to low velocity impact. Compos. Struct. 94(9), 2902-2913 (2012)

3. Phadnis, V.A., Kumar, P., Shukla, A., Roy, A., Silberschmidt, V.V.: Optimising curvature of carbon fibrereinforced polymer composite panel for improved blast resistance: finite-element analysis. Mater. Design. 57, 719-727 (2014)

4. Tan, W., Falzon, B.G., Chiu, L.N.S., Price, M.: Predicting low velocity impact damage and compressionafter-impact (CAI) behaviour of composite laminates. Compos. A: Appl. Sci. Manuf. 71, 212-226 (2015)

5. Naghipour, P., Pineda, E.J., Arnold, S.M.: Simulation of lightning-induced delamination in un-protected CFRP laminates. Appl. Compos. Mater. 23(4), 523-535 (2016)

6. Yin, J.J., Chang, F., Li, S.L., Yao, X.L., Sun, J.R., Xiao, Y.: Lightning strike ablation damage influence factors analysis of carbon fiber/epoxy composite based on coupled electrical-thermal simulation. Appl. Compos. Mater. 24(5), 1089-1106 (2017)

7. Yin, J.J., Chang, F., Li, S.L., Yao, X.L., Sun, J.R., Xiao, Y.: Experimental and numerical simulation analysis of typical carbon woven fabric/epoxy laminates subjected to lightning strike. Appl. Compos. Mater. 24(6), 1353-1372 (2017)

8. Yin, J.J., Li, S.L., Yao, X.L., Chang, F., Li, L.K., Zhang, X.H.: Lightning strike ablation damage characteristic analysis for carbon Fiber/epoxy composite laminate with fastener. Appl. Compos. Mater. 23(4), 821-837 (2016)

9. Chemartin, L., Lalande, P., Peyrou, B., Cahzottes, A., Elias, P.: Direct affects of lightning on aircraft structure: analysis of the thermal, electrical and mechanical constraints. J. Aerosp. Lab (5) (2012). https://pdfs.semanticscholar.org/ab62/8a5478499fb696f1118a00b859f31c8b3927.pdf

10. 1980 direct lightning strike data. NASA Technical Memorandum 81946, NASA Langley Research Centre, Hampton, VA (1982)

11. 1981 direct lightning strike data. NASA Technical Memorandum 83273, NASA Langley Research Centre, Hampton, VA, (1982)

12. 1982 direct lightning strike data. NASA Technical Memorandum 84626, NASA Langley Research Centre, Hampton, VA, (1983)

13. Lalande, P., Bondiou-Clergie, A., Laroche, P.: Studying aircraft lightning strokes. Aerosp. Eng. 94, 39-42 (1999)

14. Moreau, J., Alliot, J., Mazur, V.: Aircraft lightning initiation and interception from in situ electric measurements and fast video observations. J. Geophys. Res. 97, 903-912 (1992)

15. Aerospace Recommended Practice ARP 5412. Aircraft Lightning Environment and Related Test Waveforms, 1999. SAE

16. Aerospace Recommended Practice ARP 5414. Aircraft Lightning Zoning, 1999. SAE

17. Munoz, R., Delgado, S., Gonzalez, C., Lopez-Romano, B., Wang, D., Llorca, J.: Modelling lightning impact thermo-mechanical damage on composite materials. Appl. Compos. Mater. 21(1), 149-164 (2014)

18. Kawakami, H.: Lightning strike induced damage mechanisms of carbon fiber composites. PhD Thesis, University of Washington (2011)

19. Kawakami, H., Feraboli, P.: Lightning strike damage resistance and tolerance of scarf-repaired meshprotected carbon Fiber composites. Compos. Part A. 42, 1247-1262 (2011)

20. Hirano, Y., Katsumata, S., Iwahori, Y., Todoroki, A.: Artificial lightning testing on graphite/epoxy composite laminate. Compos. A: Appl. Sci. Manuf. 41(10), 1461-1470 (2010). https://doi.org/10.1016/j. compositesa.2010.06.008

21. Feraboli, P., Miller, M.: Damage resistance and tolerance of carbon/epoxy composite coupons subjected to simulated lightning strike. (98195-2400), May 2009. Presented at AIAA/ASME/ASCE/AHS/ASC Structures, Structural Dynamics and Materials Conference, Palm Springs, California

22. Feraboli, P., Kawakami, H.: Damage of carbon/epoxy composite plates subjected to mechanical impact and simulated lightning. J. Aircr. 47(0021-8669/10), 999-1012 (2010) 
23. Hosokawa, N., Ooto, T., Kubo, S., Anzai, M., Yoshiya, A., Nakagoshi, A.: Lightning strike protection for composite laminates by pitch-based carbon fibre skin. July 2013. Presented at The 19th International Conference on Composite Materials, Montreal, Canada

24. Featherston, C., Eaton, M., Evans, S., Holford, K., Pullin, R., Cole, M.: Development of a methodology to assess mechanical impulse effects resulting from lightning attachment to lightweight aircraft structures. Appl. Mech. Mater. 24-25, 129-134 (2010)

25. Evans, P.R., Featherston, C.A., Eaton, M.J., McCrory, J., Mitchard, D.: Mechanical forces due to lightning strikes to aircraft: a pseudo-stereo DIC technique for measuring full-field displacement. Presented at: 10th International Conference on Experimental Mechanics, Heriot-Watt University, Edinburgh, 1-3 September 2015. http://orca.cf.ac.uk/77054

26. Soulas, F., Espinosa, C., Lachaud, F., Guinard, S., Lepetit, B., Revel, I.: Equivalent impact set-up for lightning strike damage on composite coupons. Presented at International Conference on Composite Materials, Copenhagen, Denmark (2015)

27. Gammon, L., Falcone, A.: Lightning strike damage in polymer composites. Adv. Mater. Process. 161, 61$62(2003)$

28. Gineste, P., Clerc, R., Castanie, C., Andreu, H., Buzaud, E.: Assessment of Lightning Direct Effects Damages by Modelling Techniques. 2009. Presented at Int. Aerospace Ground Conf. on Lightning and Static Electricity, Pittsfield, USA

29. Yamashita, S., Ohsawa, I., Morita, A., Takahashi, J.: Fracture behaviour of carbon fibre reinforced polypropylene under artificial lightning strike. July 2013. Presented at The 19th International Conference on Composite Materials, Montreal, Canada

30. Dong, Q., Guo, Y., Sun, X., Jia, Y.: Coupled electrical-thermal-pyrolytic analysis of carbon fiber/epoxy composites subjected to lightning strike. Polymer. 56, 385-394 (2015)

31. Haigh, S.: Impulse effects during simulated lightning attachments to lightweight composite panels. Presented at Int. Aerospace Ground Conf. on Lightning and Static Electricity, Paris, France. (2007)

32. Gou, J., Tang, Y., Liang, F., Zhao, Z.: Carbon nanofiber paper for lightning strike protection of composite materials. Compos. Part B. 41(1359-8368), 192-198 (2010)

33. Lepetit, B., Escure, C., Guinard, S., Revel, I., Peres, G.: Thermo-mechanical effects induced by lightning on carbon fibre composite materials. Presented at Int. Aerospace Ground Conf. on Lightning and Static Electricity, Paris, France (2011)

34. Chen, F.F.: Introduction to plasma physics and controlled fusion, 3rd edn. Springer International Publishing, Switzerland (2012)

35. Reid, G.: Mechanical damage to aircraft structures from lightning strikes. Proceedings of institution of mechanical engineers. Part G: J. Aerosp. Eng. 207, 1-14 (1993)

36. Hardwick, J., Pout, A., Jones, C., Ulmann, A., Zaglauer, H.: FULMEN report: investigation of the parameters affecting mechanical forces in aluminium and CFC plates subject to simulated lightning strikes. Transport Research and Technological Development Program (1997)

37. Abdelal, G.F., Murphy, A.: A multiphysics simulation approach for efficient modeling of lightning strike tests on aircraft structures. IEEE Trans. Plasma Sci. 45(4), 725-735 (2017)

38. Rivallant, C.B., Hongkarnjanakul, N.: Failure analysis of CFRP laminates subjected to compression after impact: FE simulation using discrete interface elements. Compos. A: Appl. Sci. Manuf. 55, 83-93 (2013)

39. Hongkarnjanakul, N., Bouvet, C., Rivallant, S.: Validation of low velocity impact modelling on different stacking sequences of CFRP laminates and influence of fibre failure. Compos. Struct. 106, 549-559 (2013) S

40. de Moura, M.F.S.F., Gonçalves, J.P.M.: Modelling the interaction between matrix cracking and delamination in carbon-epoxy laminates under low velocity impact. Compos. Sci. Technol. 64(7-8), 1021-1027 (2004)

41. Higuchi, R., Okabe, T., Nagashima, T.: Numerical simulation of progressive damage and failure in composite laminates using XFEM/CZM coupled approach. Compos. A: Appl. Sci. Manuf. 95, 197-207 (2017)

42. Catalanotti, G., Camanho, P.P., Marques, A.T.: Three-dimensional failure criteria for fiber-reinforced laminates. Compos. Struct. 95, 63-79 (2013)

43. Abdelal, G., Murphy, A.: Nonlinear numerical modelling of lightning strike effect on composite panels with temperature dependent material properties. Compos. Struct. 109, 268-278 (2014) 